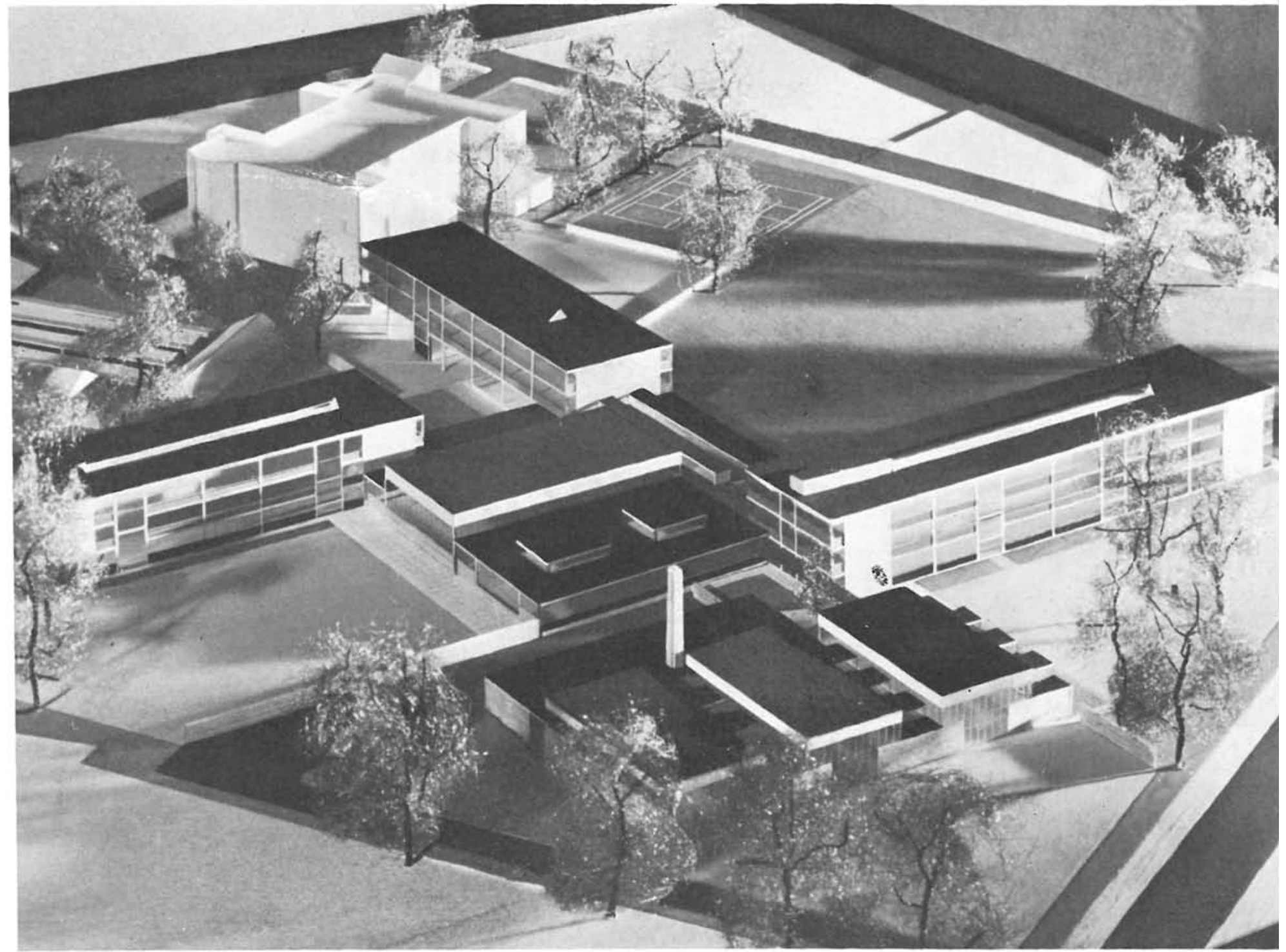

\title{
escuela mayfield, en Putney
}

POWELL y MOYA, arquirectos

$141-17$

Aprovechando la circunstancia de que los alrededores de la escuela Mayfield habían quedado destruídos después de la última guerra mundial, este Centro ha adquirido un solar contiguo de 25.000 metros cuadrados, ampliando, de este modo, su capacidad para 1.620 alumnas más, y renovando sus instalaciones, de forma que esta escuela se ha convertido en uno de los Centros modelo de educación para la juventud femenina en Inglaterra. 


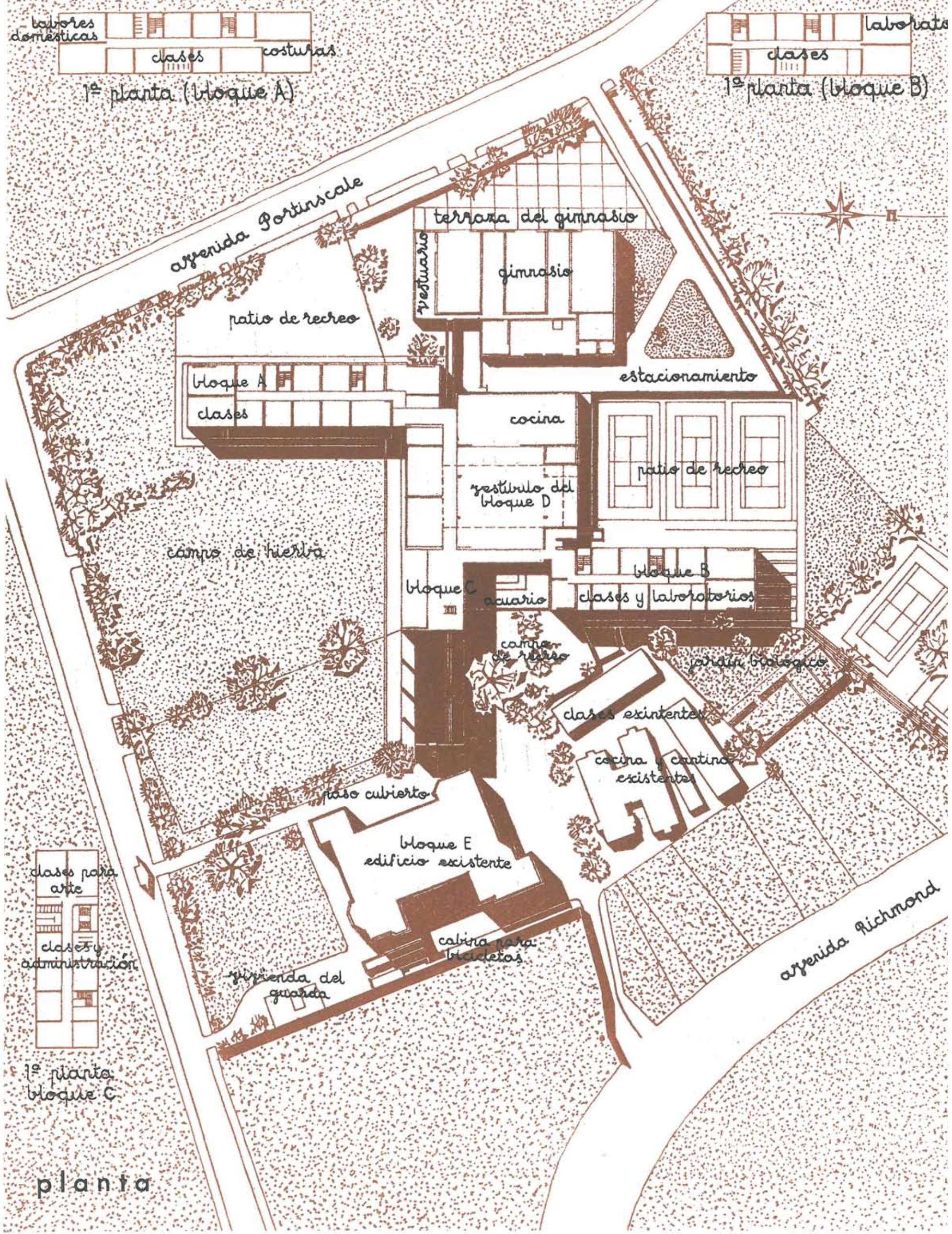



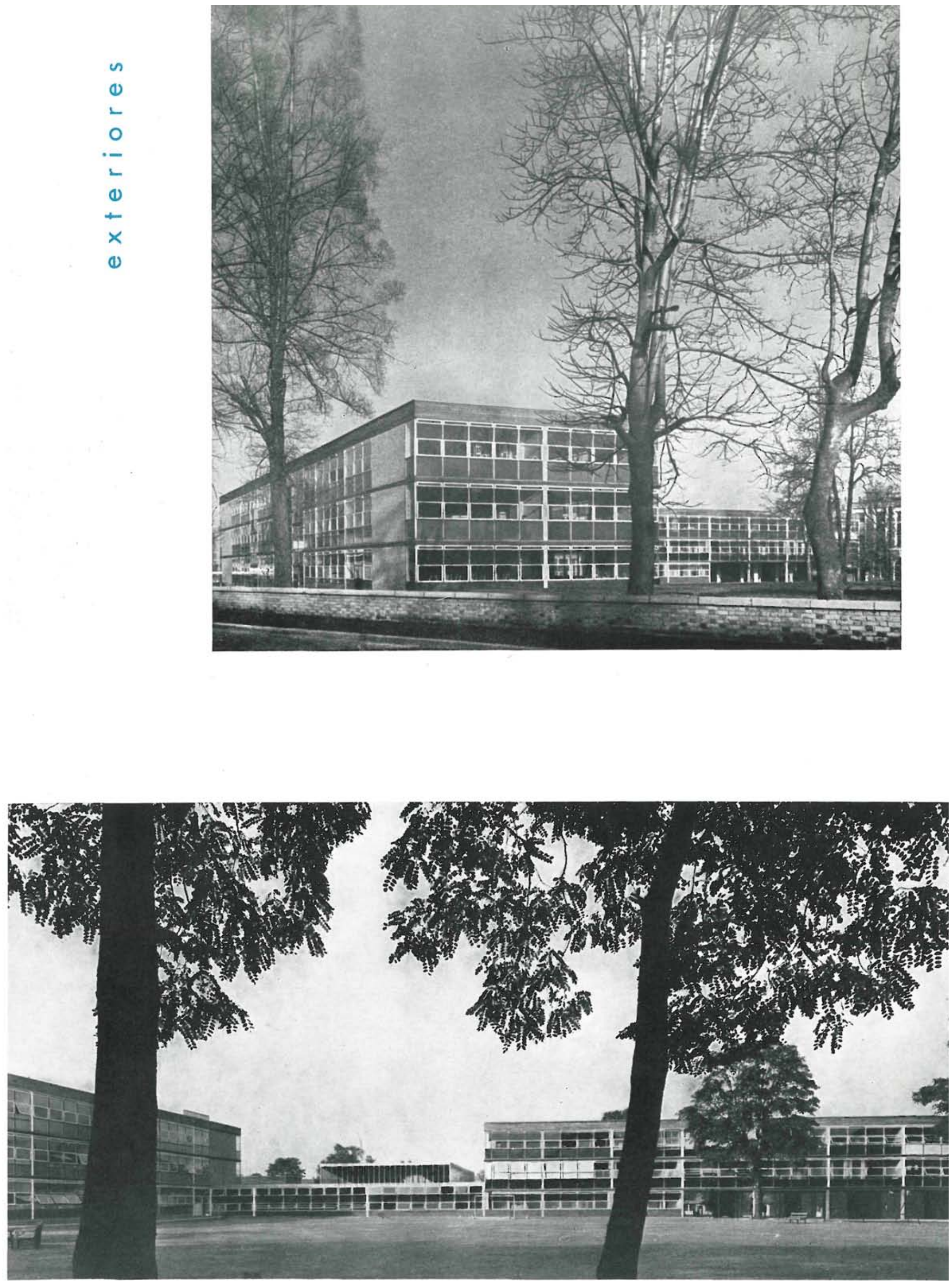


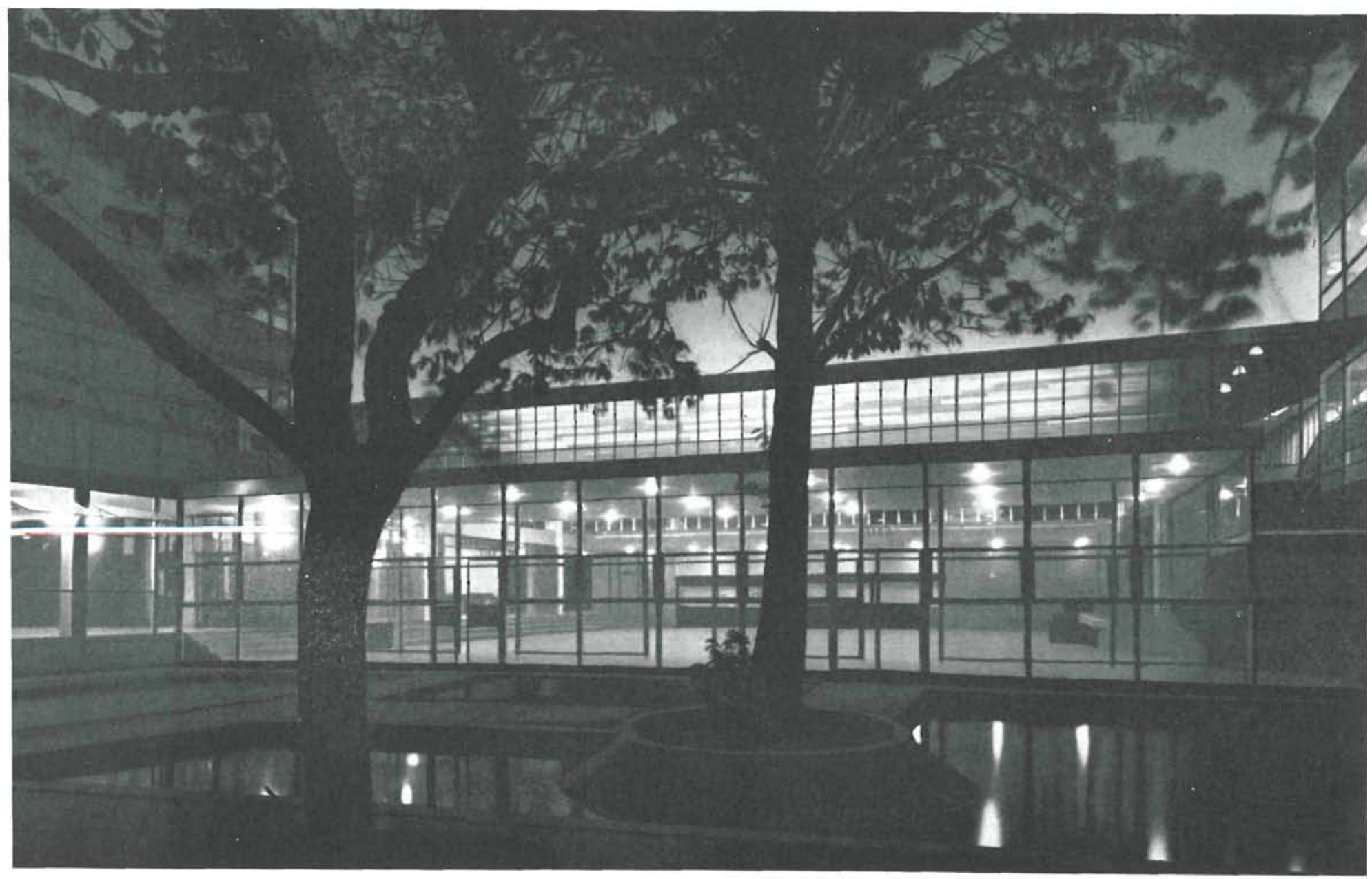

En este proyecto de ampliación se ha procurado armonizar, en lo posible, las nuevas construcciones con las ya existentes. Se han construído tres bloques para clases por el sistema de un pasillo central y aulas a uno y otro lado. Estos bloques se comunican entre sí por medio de un edificio central, el cual contiene un amplio hall y una amplia sala que hace las veces de comedor o salón de actos, según lo requieran las circunstancias.

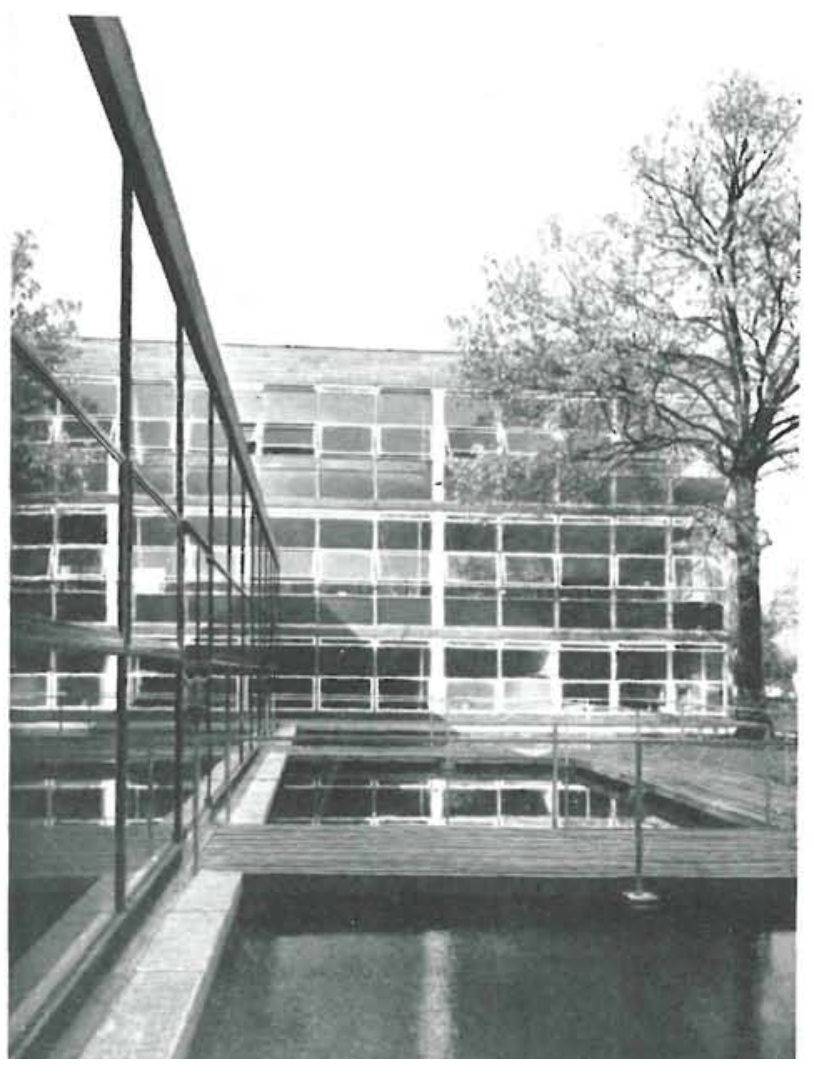




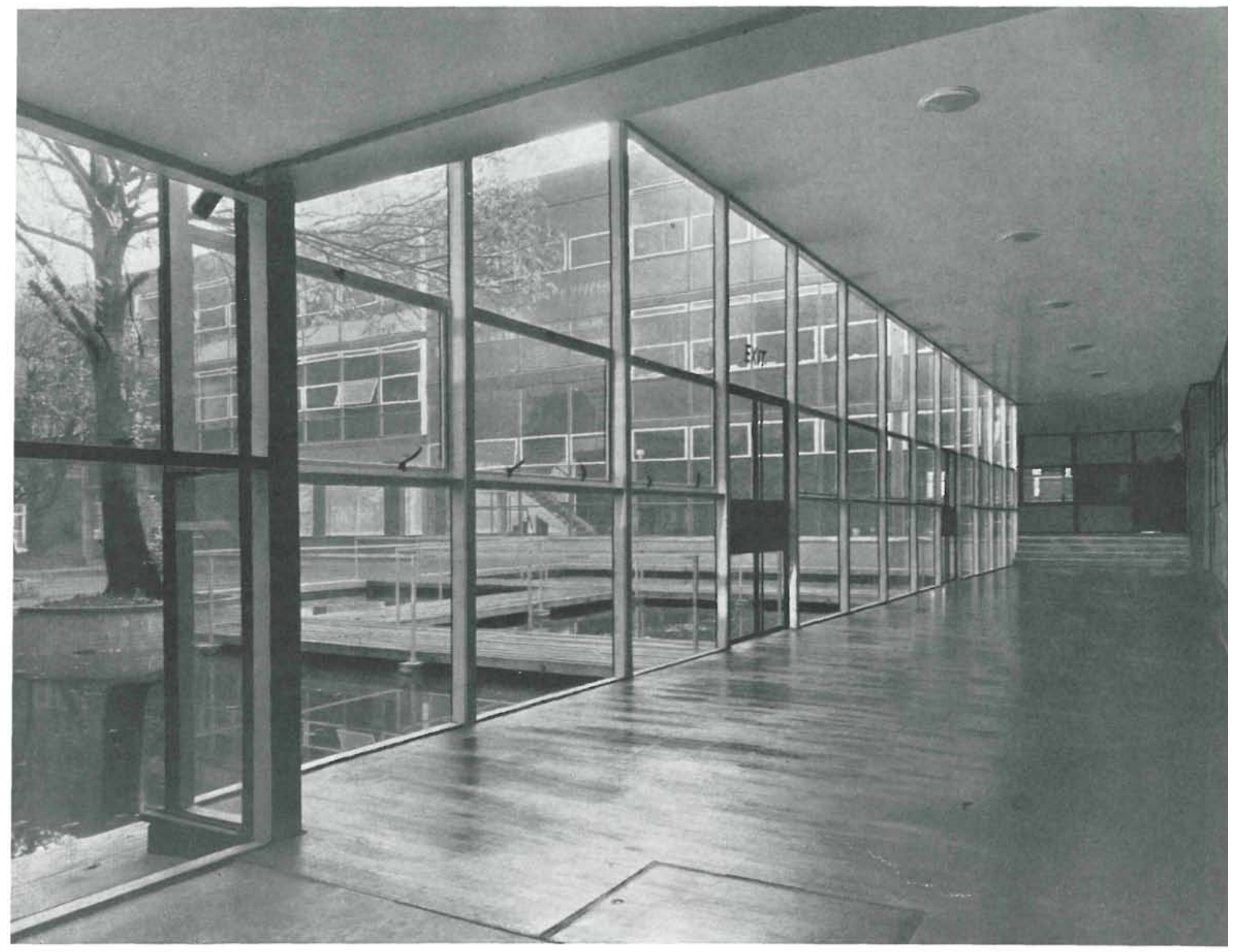

vestíbulo y clases

El conjunto alberga también un gimnasio y, además, un pequeño cuerpo de edificio que aloja los servicios de la calefacción.

El proyecto se realizó en una época en que escaseaba el acero y, por ello, en todos los edificios se ha ido a la solución constructiva de hacer la estructura con muros de fábrica de ladrillo de un pie.

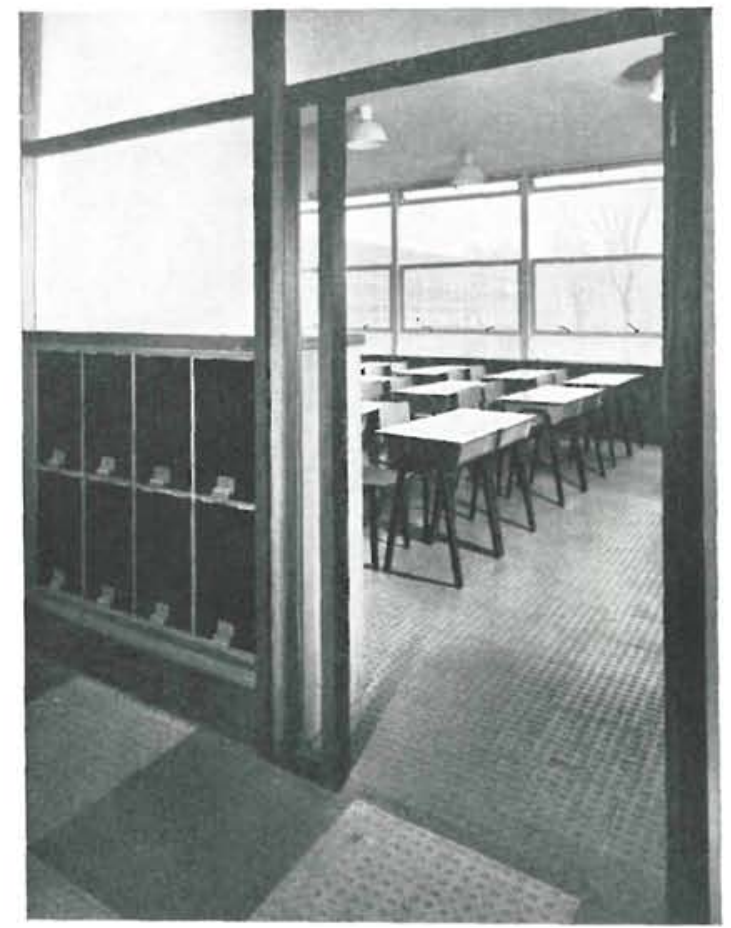



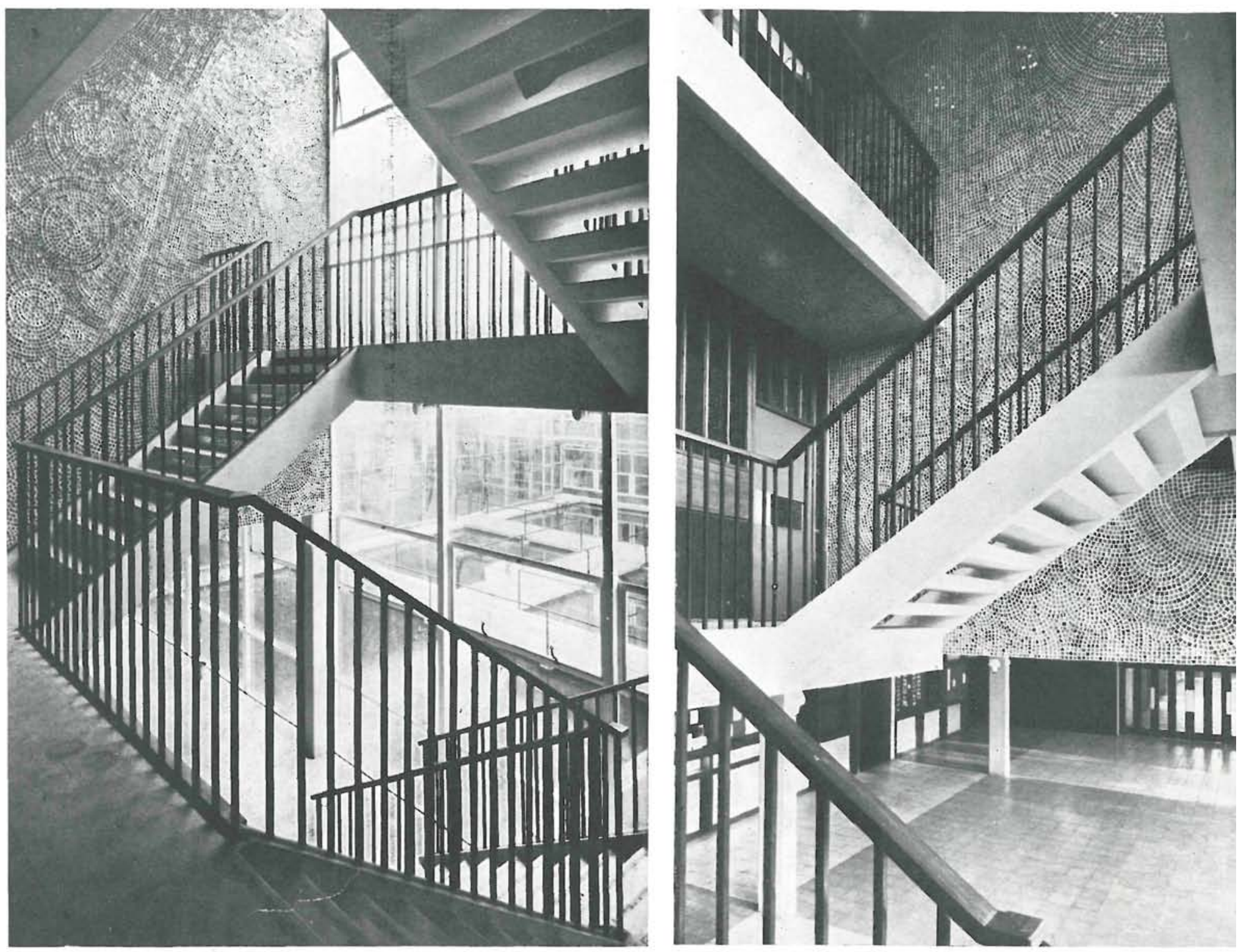

Como se precisaban amplios ventanales, estos muros resistentes se han colocado perpendiculares a fachada. De esta forma - tal como se pretendíalos ventanales van de suelo a techo sin encontrar cargaderos.

El forjado es de hormigón armado pretensado; el cerramiento exterior, de cristal; la carpintería interior, de madera, y la exterior, de acero galvanizado sobre cerco de madera; las cubiertas son de madera, excepto en la nave de la calefacción, que es de hormigón armado.

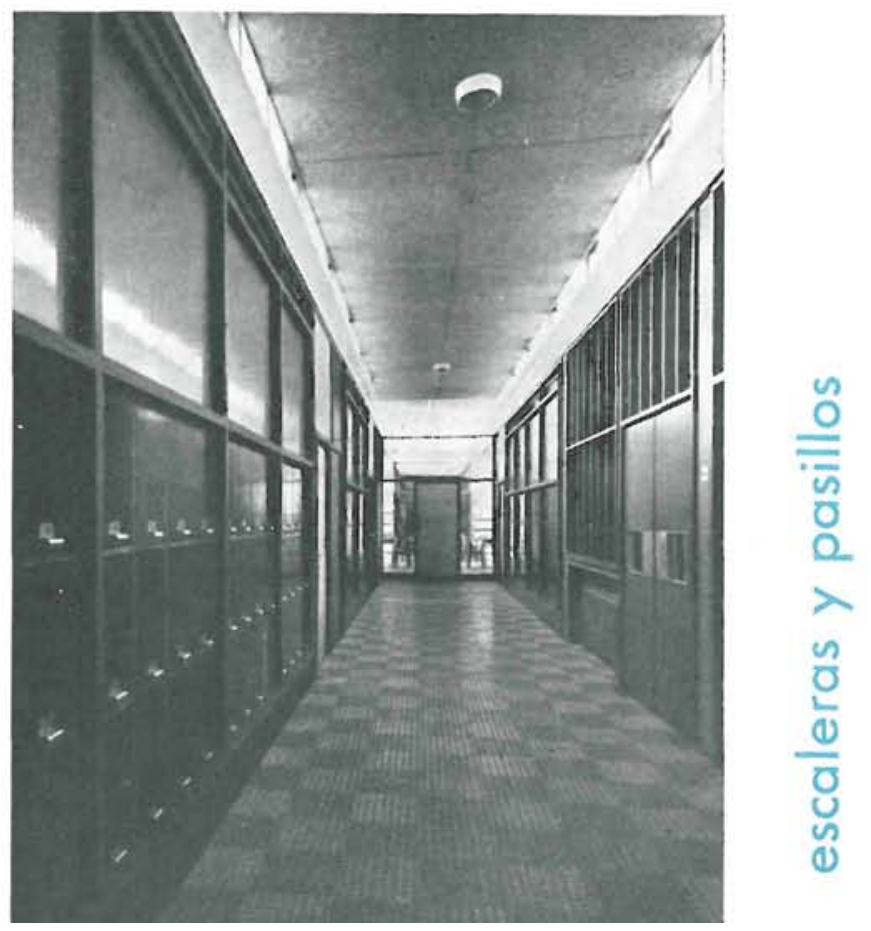




\section{vigas trianguladas}

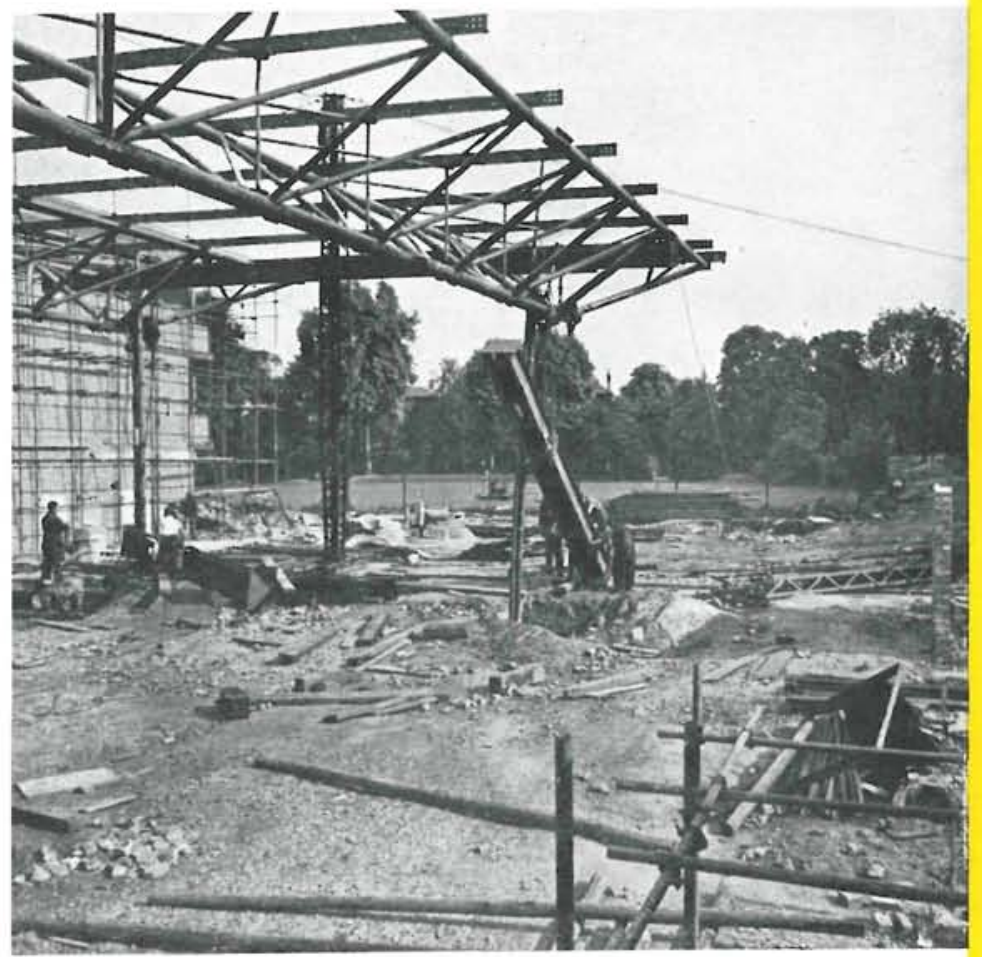

Es de destacar la estructura de cubierta del vestíbulo y salón de actos, formada por una serie de vigas, en $\mathrm{V}$, de elementos triangulados de tubos metálicos.

Una de las cosas que más se han cuidado en este proyecto son los colores: interiormente dominan el gris claro y el amarillo con los techos en color blanco. Los tonos fuertes se han empleado en pequeñas zonas; por ejemplo: en las ranuras de ventilación encima de las ventanas. La mayoría de las puertas llevan revestimiento plástico: rojo en las entradas a la caja de escalera, blanco en las clases y negro en los servicios. Las puertas de los armarios en los pasillos van en gris oscuro, verde y negro.

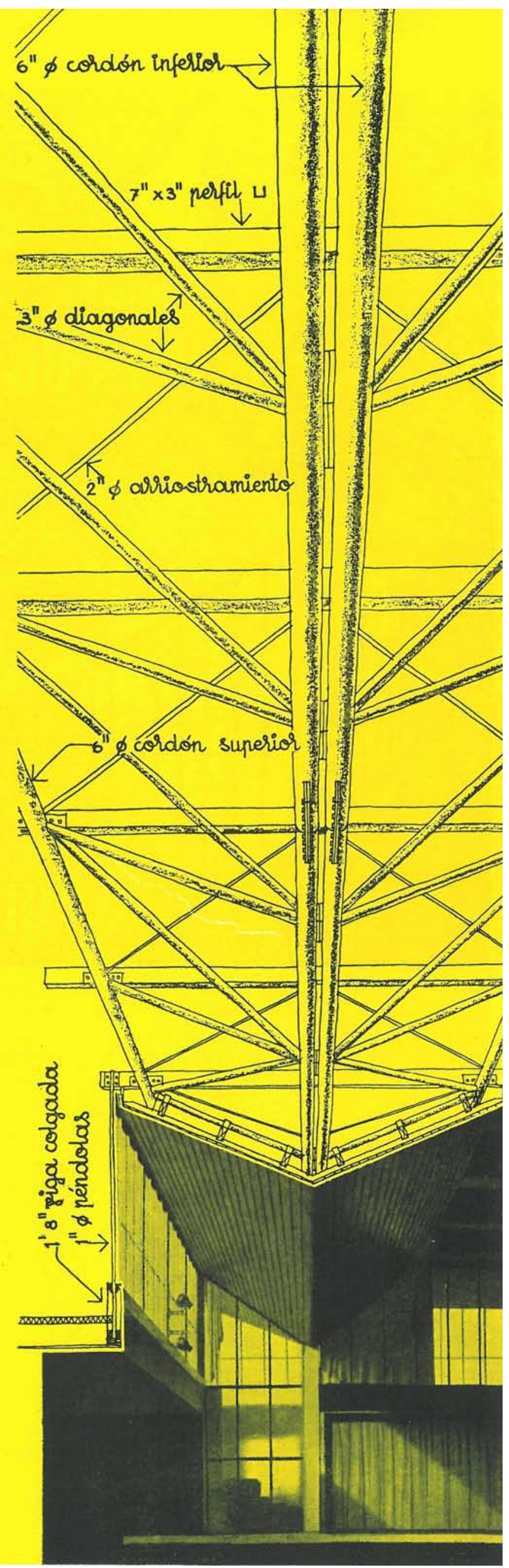



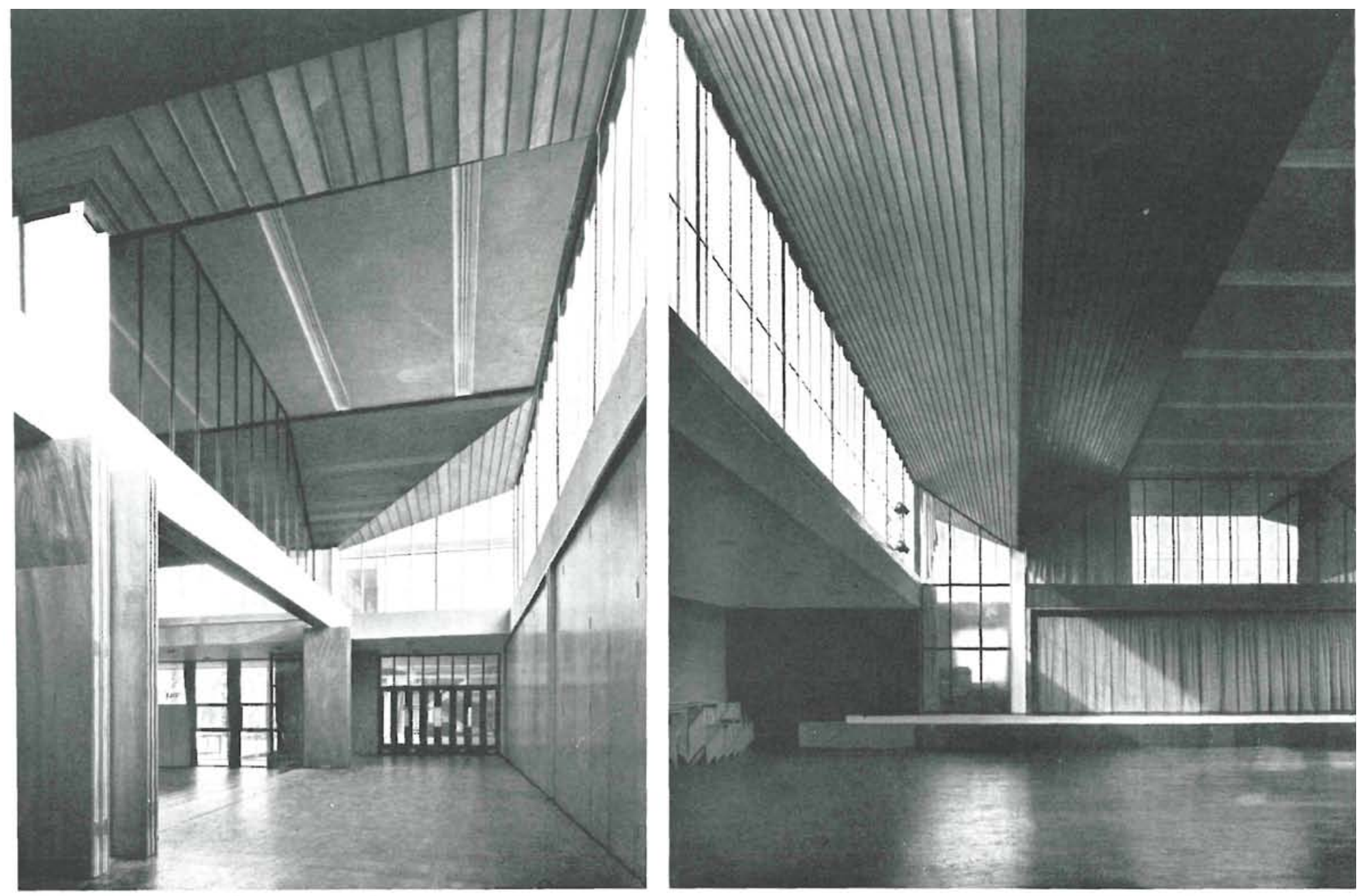

hall y salón

Los pavimentos interiores son de terrazo, excepto en el gimnasio, que es un revestimiento tipo «Gurjun» sobre metal.

Ya que los $36.000 \mathrm{~m}^{2}$ de solar adquirido para esta ampliación eran parte de un parque, se han conservado los árboles y se ha hecho un jardín adecuado a este tipo de vegetación, intercalando estanques con plantas acuáticas que tiñen el ambiente de paz y reposo muy propio para reponer a las alumnas de las fatigas de las jornadas de trabajo. La superficie de que disfruta cada alumna es de $7 \mathrm{~m}^{2}$, incluída la zona de juego. 

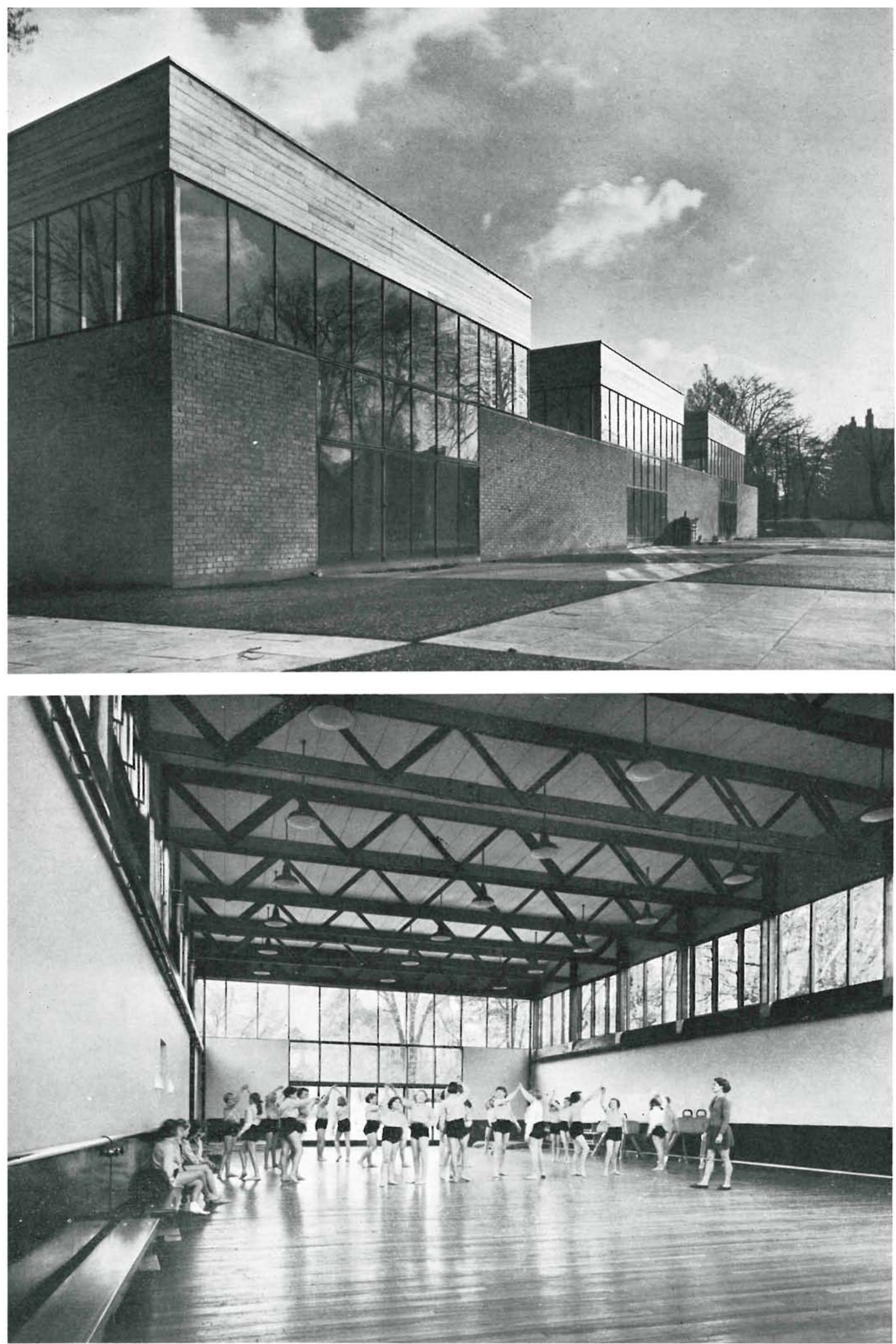

는 